\title{
CdS/CdSSe quantum dots in glass matrix
}

\author{
R S SONAWANE, S D NAIK, S K APTE, M V KULKARNI and B B KALE* \\ Department of Information Technology, Centre for Materials for Electronics Technology (C-MET), \\ Panchawati, Pune 411 008, India
}

\begin{abstract}
The compositions containing 55 and $60 \%$ of silica have been formulated for preparation of glass filters having sharp cut-off at 475 and $575 \mathrm{~nm}$. To achieve cut-off at these wavelengths, the glasses have been doped with $\mathrm{CdS} / \mathrm{CdSSe}$ and melted at $1200-1300^{\circ} \mathrm{C}$. The glass samples were transparent and pale yellow in colour due to presence of CdS/CdSSe tiny nano crystal (Q-dots). In situ growth of CdS/CdSSe nano crystals imparts the yellow/orange/red colour to these glasses. Optical study shows that as prepared glasses have optical cut-off in the range 350-370 $\mathrm{nm}$. The linear crystal growth of CdS/CdSSe in glasses exhibits red shift in optical cut-off. The optical filter having cut-off at $475 \mathrm{~nm}$ can be prepared by doping CdS and cut-off filter of wavelength $575 \mathrm{~nm}$ by CdSSe. The TEM results show that the CdS/CdSSe nano crystals (Q-dots) ranging from $2-5 \mathrm{~nm}$ are uniformly distributed into the glass matrix.
\end{abstract}

Keywords. CdS; CdSSe; nanocrystals; glasses; optical filters.

\section{Introduction}

Today nanostructured materials and quantum dots have immense importance in the field of optoelectronics and biomedical. The quantum dots in solution have been effectively used in LED, solar systems and biomedical applications. Quantum dots are generally unstable and attempts have been made to stabilize these quantum dots using glass and polymer matrix. Semiconductor doped glasses (SDGs) have attracted great interest in the past few years due to their nonlinear optical characteristics. The potential application of these glasses are in the field of optoelectronics and optical cut-off filters (Ekimov and Onushchenko 1981; Borrelli et al 1987; Potter and Simmons 1988; Hache et al 1989; Santhi and Trojanek 2005). The optical properties of these glasses depend on the size and shape of the semiconductor nanocrystals. Semiconductor particles below $10 \mathrm{~nm}$ in diameter exhibits a well known quantum size effect which is the origin of many linear and nonlinear optical properties useful in optoelectronics and optical switching devices. The CdS, CdSSedoped glasses are colourless when made by the usual glass making process (Persans et al 2001) and obtain their colour only after reheating. The growth of semiconductor nanocrystals embedded in glass matrix occurs via the process of nucleation and crystal growth mechanism, which imparts colour to the glasses. The properties of such nanoparticles are intrinsically interesting, allowing us to test models for size-dependent electronic and structural

*Author for correspondence

(kbbb1@yahoo.com, bbkale@cmet.gov.in) effects. Semiconductor nanoparticles also have potential applications for linear and nonlinear optical devices (Ekimov et al 1993; Norris et al 1994; Persans et al 2001). Many researchers have given emphasis on the characterization of the glasses rather than compositional study. However, very few of them have studied the crystal growth kinetics of these types of glasses with different glass compositions. The dissolution of $\mathrm{CdS}$ and $\mathrm{CdSSe}$ in glass matrix is a critical phenomenon, which entirely depends on the base glass composition. In the present investigation, new glass composition has been tailored and the tiny nanocrystals of $\mathrm{CdS} / \mathrm{CdSSe}$ were grown thermally in glass matrix at different temperatures and time intervals. By using this composition, optical cut-off filters having sharp cut-off at 475 and $575 \mathrm{~nm}$ in UV-visible were fabricated in order to study the possible photonic application of these glasses.

\section{Experimental}

\subsection{Glass preparation}

The new glass composition, $55 \mathrm{SiO}_{2}, 2-7 \mathrm{Na}_{2} \mathrm{O}, 20-30$ $\mathrm{K}_{2} \mathrm{O}$, 5-10 ZnO, 1-8 $\mathrm{B}_{2} \mathrm{O}_{3}, 1 \mathrm{TiO}_{2}, 4-8 \mathrm{BaO}$, was used for the study. The different raw materials were weighed as per the above composition and mixed in pestle mortar to obtain homogeneous mixture. The amount and type of dopants like $\mathrm{CdS}$, Se, S were selected depending on the type of filter and added into the composition followed by further mixing. The composition prepared was taken in recrystallized alumina crucible and melted in an electrically heated muffle furnace (Thermolyne-U3200) at 1300$1500^{\circ} \mathrm{C}$. The melt was soaked for $3-4 \mathrm{~h}$. During soaking 
time, the molten glass was stirred 3-4 times to achieve homogeneous distribution of semiconductors by using a special type of ceramic rod which is thermally stable at high temperature. After refining, the glass melt was quenched in air on hot brass plate and processed immediately for annealing. The glass was annealed in programmable furnace at its transition temperature $\left(T_{\mathrm{g}}\right)$ i.e. 570 $580^{\circ} \mathrm{C}$ and slowly cooled to room temperature to remove the stresses. The glass obtained was polished with emery papers of different grades i.e. 120, 240, $320 \mu$ on glass polishing machine. The polished glass samples were heat treated at different temperatures for crystal growth and repolished again.

\subsection{Characterization}

The glasses obtained were characterized by different techniques. The optical characterization was carried out using UV-visible Spectrophotometer (Hitachi, U-3210 model). Thermal properties were studied by differential scanning calorimetry (Mettler Toledo DSC-7) to determine glass transition temperature $\left(T_{\mathrm{g}}\right)$ and thermo mechanical analyser (Perkin Elmer TMA-7) was used to determine the thermal expansion coefficient of the glass. The particle size of $\mathrm{CdS}$ and CdSSe was measured by using TEM (JEOL 100 CX).

\section{Results and discussion}

The melting of optical quality glasses for optical system is quite difficult because of its requirement of homogeneity. To achieve good homogeneity, good melting facility is essential. The melting of the semiconductor doped glasses is quite critical than the normal optical glasses. Many compositions have been melted and few of them have optimized. Among the compositions optimized, the composition containing silica content $55 \%$ and $60 \%$ (by weight) has shown good homogeneity (Persans et al 2001). In the present study these same compositions have been selected for making optical cut-off filters.

At optimized conditions the glasses were prepared, polished and filters having cut-off at 475 and $575 \mathrm{~nm}$ were fabricated. The glass filter (samples) having cut-off wavelength of $475 \mathrm{~nm}$ are hereafter referred to as CM475 and samples having cut-off wavelength of $575 \mathrm{~nm}$ are referred to as CM-575. The results of these glasses are summarized in table 1 . DSC showed $T_{\mathrm{g}}$ of these glasses at $575-580^{\circ} \mathrm{C}$ and TMA showed thermal expansion at around $11 \times 10^{-6} / \mathrm{K}$. There was no significant change in thermal properties after growth of semiconductors. This may be because of the low concentration of semiconductors i.e. $<1 \%$. The density of the glasses observed in the range $2 \cdot 5-3 \mathrm{~g} / \mathrm{cc}$ where there was no change after crystal growth.

\subsection{Optical properties}

Figure 1(a and b) depicts the behaviour of the optical absorption of glasses, CM-475 and CM-575, at different temperatures. The glass, CM-475, was heat treated at different temperatures for $8 \mathrm{~h}$.

Table 1. Properties of glass filters.

\begin{tabular}{lcc}
\hline Properties & $\mathrm{CM}-475$ & $\mathrm{CM}-575$ \\
\hline Density $(\mathrm{g} / \mathrm{cc})$ & $2 \cdot 5-3$ & $2 \cdot 5-3$ \\
Transition temperature $\left(T_{\mathrm{g}}\right.$ in $\left.{ }^{\circ} \mathrm{C}\right)$ & 580 & 574 \\
Thermal expansion $\left(10^{-6} / \mathrm{K}\right)$ & 11 & 11 \\
Refractive index & 1.563 & 1.563 \\
Absorption edge cut-off $(\mathrm{nm})$ & 475 & 575 \\
Chemical stability & Good & Good \\
\hline
\end{tabular}
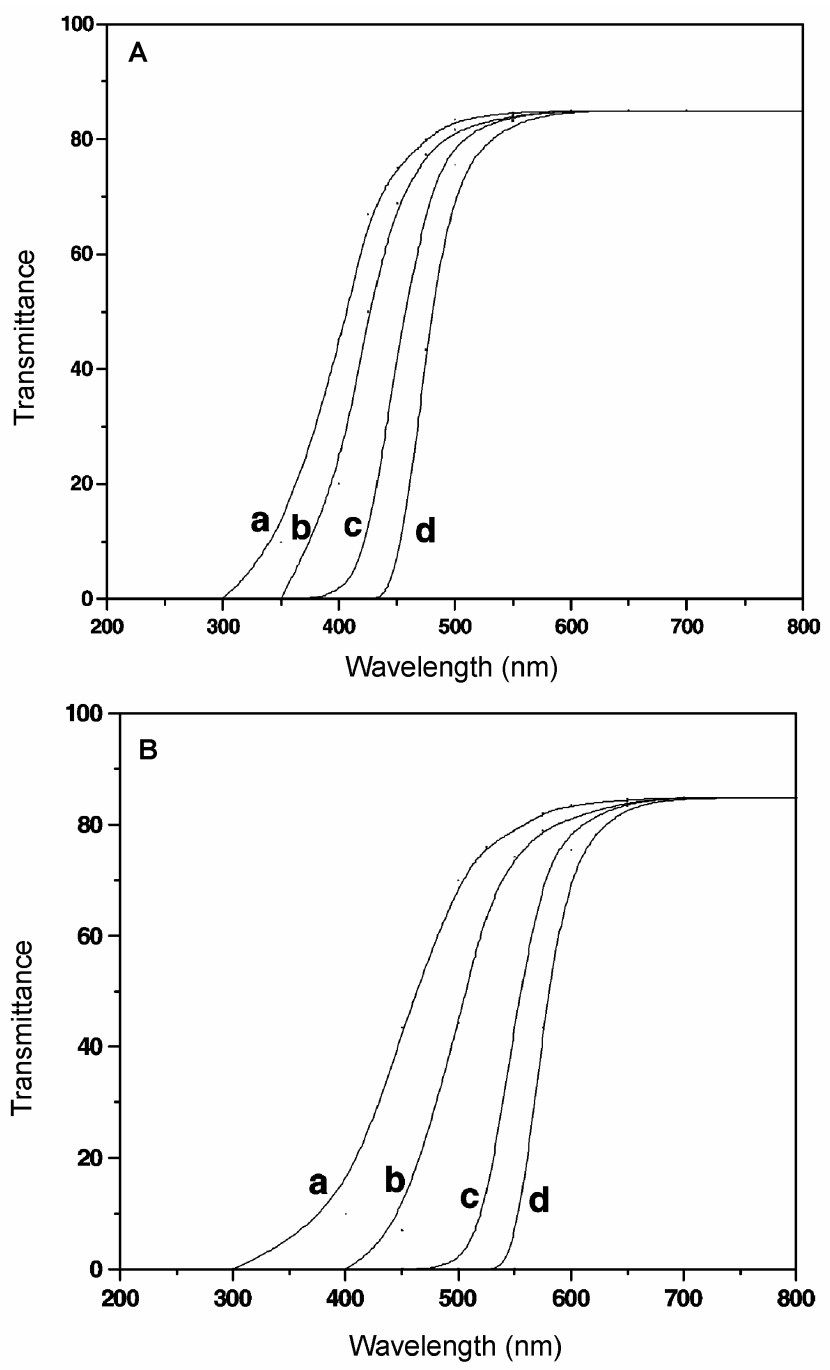

Figure 1. UV-visible transmission spectra of glass filter $\mathbf{A}$ CM-475 nm, heated at various temperatures: a. $R T$, b. $550^{\circ} \mathrm{C}, \mathrm{c}$. $575^{\circ} \mathrm{C}$ and $\mathrm{d} .600^{\circ} \mathrm{C}$ for $8 \mathrm{~h}$ and B. CM- $575 \mathrm{~nm}$ heated at various temperatures: a. $R T$, b. $550^{\circ} \mathrm{C}$, c. $575^{\circ} \mathrm{C}$ and d $600^{\circ} \mathrm{C}$. 
Table 2. Optical cut-offs and bandgap at different striking conditions.

\begin{tabular}{lccc}
\hline Glass filter & Striking temperature $\left({ }^{\circ} \mathrm{C}\right)$ & Wavelength $(\mathrm{nm})$ & Bandgap $(\mathrm{eV})$ \\
\hline $475 \mathrm{~nm}(\mathrm{CdS})$ & Before striking & 397 & $3 \cdot 12$ \\
& 550 & 418 & $2 \cdot 97$ \\
& 575 & 450 & $2 \cdot 76$ \\
& 600 & 475 & $2 \cdot 61$ \\
$575 \mathrm{~nm}(\mathrm{CdSSe})$ & Before striking & 450 & $2 \cdot 76$ \\
& 550 & 497 & $2 \cdot 49$ \\
& 575 & 549 & $2 \cdot 26$ \\
& 600 & 575 & $2 \cdot 16$ \\
\hline
\end{tabular}

Curve ' $a$ ' in the UV spectra corresponds to sample that was without heat treatment; curves b-d correspond to glass sample heated to 550,575 and $600^{\circ} \mathrm{C}$, respectively. It can be clearly seen that the shape of the absorption edge becomes steeper with increasing striking temperature. This suggests that the crystal size of CdS was increasing with temperature. The steepness also shows uniform growth of the crystals. The non-uniform growth with different shape crystallites generally gives broad absorption (Murugan et al 2001). It also reduces the optical transmittance, which ultimately hampers the optical properties. It was also observed that the striking conditions are dependent on the quenching time of the glass. The absorption edge at $397 \mathrm{~nm}$ was observed for the glass without heat treatment. Such absorption can be attributed to slight crystallization of the $\mathrm{CdS}$ nanocrystallites that occurs during quenching. The glasses doped with CdSSe i.e. CM-575 (figure 1b) shows similar absorption edge behaviour even though shapes of the edges differ slightly. In case of pure CdS doped glass, the absorption cut-off attained up to $495 \mathrm{~nm}$ beyond which there was a precipitation leading to decrease in the optical transmittance. The longer heat treatment at lower temperatures had no significant effect. There must be an optimum time at a particular temperature where $\mathrm{CdS}$ does not grow beyond a particular size. However, it was observed that the glass samples with initial low temperature $\left(520-550^{\circ} \mathrm{C}\right)$ heat treatment at longer time exhibited better particle density and uniformity, which may be due to the homogeneous nucleation. This was observed in all types of the glass samples. This is the first time we are reporting the sharp absorption edge cut-offs at a lower striking temperature as compared with the high striking temperature (up to $700^{\circ} \mathrm{C}$ ) reported in the literature (Persans et al 2001). This novel base glass composition, in general, exhibits chemical and thermal stability which made us to study their structural and optical properties.

The nucleation of new particles ends when the supply of either $\mathrm{Cd}$ or $\mathrm{S} / \mathrm{Se}$ in the glass matrix begins to deplete. At this time, smaller particles will become less stable resulting in dissolution back into the glass matrix and large particles grow at the expense of small particles. This final stage is known as coarsening or ripening stage (Lifshitz and Slyozov 1961; Potter and Simmons 1988). a

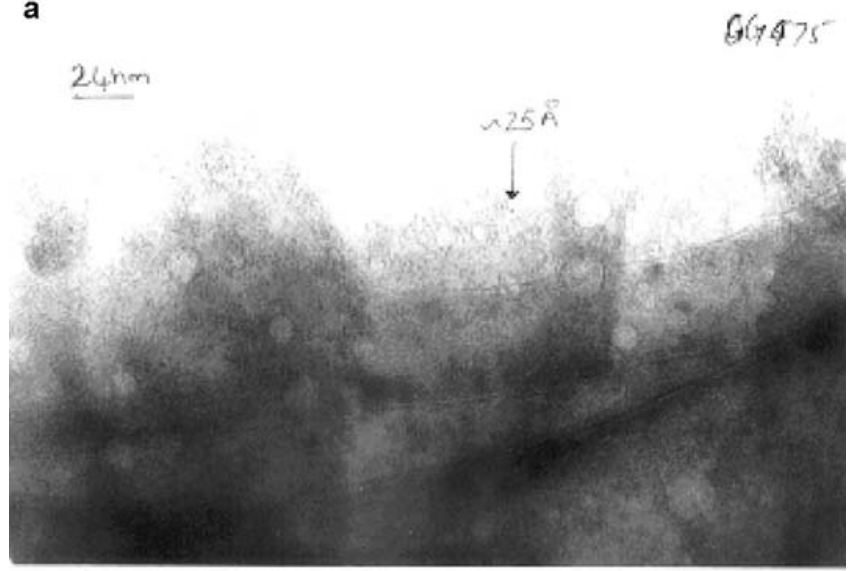

b

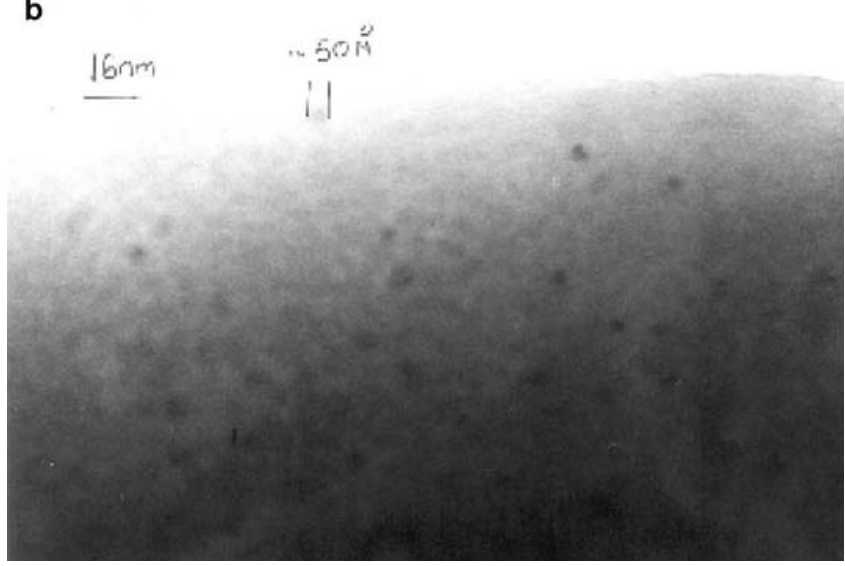

Figure 2. TEM images of glass filter a. CM-475 nm and b. CM-575 nm.

The fact that the magnitude of the absorption peak begins to decrease after a few hours $\left(550^{\circ} \mathrm{C}\right)$ of heat treatment and becomes steady at $600^{\circ} \mathrm{C}(20 \mathrm{~h})$ and is consistent with the ripening phenomenon. The sharp leading edge of the absorption shoulder is consistent with the large-particle cut-off in the Lifshitz-Slyozov distribution (Lifshitz and Slyozov 1961; Potter and Simmons 1988) and the crystal size dependence of excited energy states.

The effect of striking temperature on the UV-visible absorption edge at various temperatures has been studied and the results are summarized in table 2 . 


\subsection{Structural characterization}

X-ray diffraction patterns were obtained using Rigaku Model and reflection parameters are in good agreement with the reported values (Borrelli et al 1987; Murugan et al 2001). Diffraction scans over a range of $2 \theta$ from 20 $80^{\circ}$ are shown in figures 2 (a) and (b) for the glasses, CM475 and CM-575, respectively. In both these glasses, one relatively diffuse peak was observed on a sloping background that is the portion of the broad 'halo' characteristic of diffraction of nanocrystals in glass. This peak was observed in both types of glasses at same theta values $\left(2 \theta \sim 23-37^{\circ}\right)$, which implies the nanocrystalline nature of CdS and CdSSe. The other three peaks were identified as a reflection from (102), (110) and (103) planes of hexagonal structure (Hache et al 1989; Murugan et al 2001). The other peaks obtained might be because of the growth of the quartz crystals. Since silica is a major constituent in the glass, the growth of quartz is quite obvious. The particle size was calculated using Scherrer formula (Hache et al 1989) using the prominent peak. From XRD, the
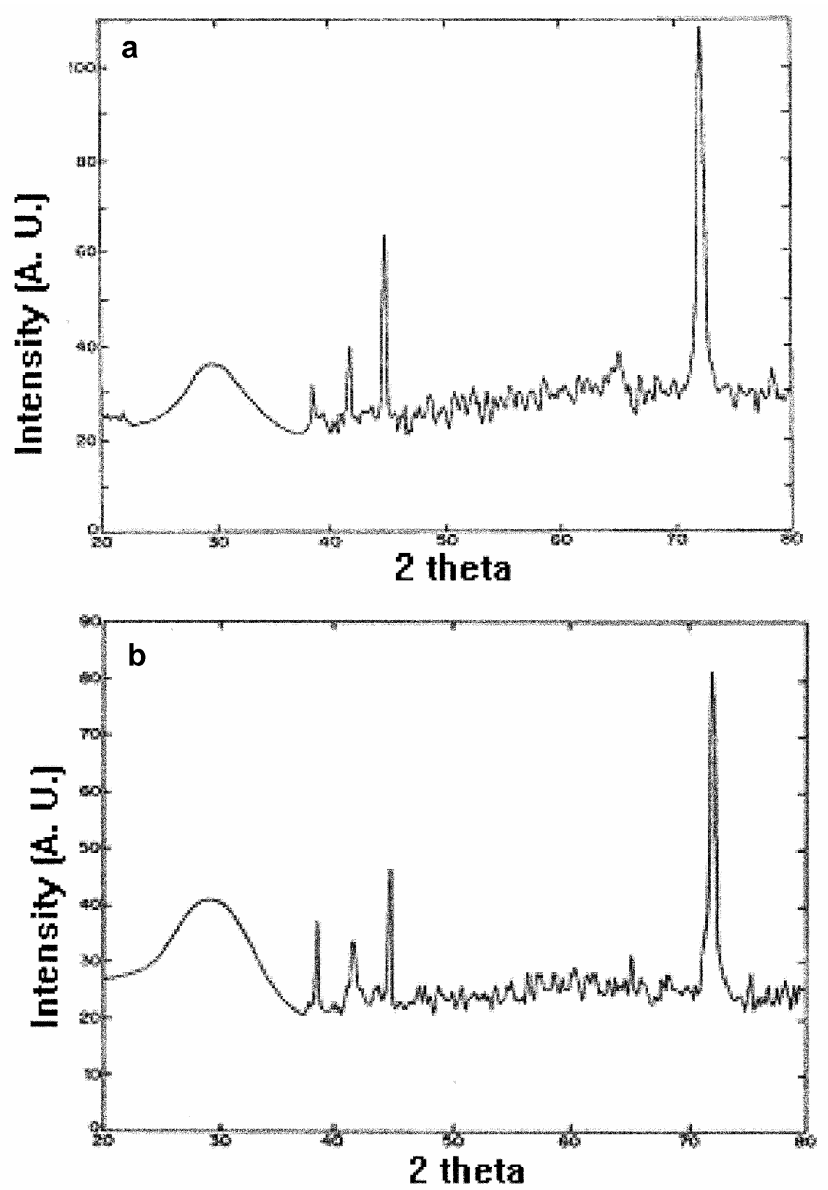

Figure 3. XRD patterns of glasses a. CM-475 and b. CM-575. glasses, CM-475 and CM-575, were found to have crystallite sizes 5 and $7 \mathrm{~nm}$, respectively.

\subsection{Surface morphology of glasses}

The TEM images of the CM-475 and CM-575 glass filters is as shown in figures $3 a$ and $b$. In both the images, careful observation of images shows that spherical shaped particles can be easily seen in the glass matrix. These spherical particles are nothing but the $\mathrm{CdS}$ nanocrystals in CM-475 and CdSSe nanocrystals in CM-575 types of glasses. The particle size of semiconductors obtained by TEM was 2.5 and $5 \mathrm{~nm}$ for the glass, CM-475 and CM575 , respectively. TEM pictures also give an idea about uniform distribution of $\mathrm{CdS}$ and $\mathrm{CdSSe}$ crystallites into the glass matrix.

\section{Conclusions}

One of the potential applications for nanoparticle composites such as $\mathrm{CdS} / \mathrm{CdSSe}$ in glass is as a non-linear absorbing element in optical switches. The objective of the materials development is to concentrate as much oscillator strength as possible into a narrow energy range. One path of this goal is to make a narrow size distribution of small particles. This will be dependent on the ideal glass composition favourable to uniform and controlled crystal growth. In view of this, the new glass composition was optimized and the nano-crystals of $\mathrm{CdS} / \mathrm{CdSSe}$ were grown thermally in glass matrix at different temperatures. There was no appreciable change observed in thermal properties after striking process. In X-ray pattern of all glass samples, one relatively diffuse peak was observed on a sloping background that is the portion of the broad 'halo' characteristic of diffraction of nanocrystals in glass, which implies the nanocrystalline nature of the $\mathrm{CdS}$ and CdSSe. The particle size of semiconductors obtained by TEM was 2.5 and 5 for the glasses, CM-475 and CM575 , respectively. TEM pictures clearly indicate that all crystallites of $\mathrm{CdS}$ and CdSSe are uniformly distributed in the glass matrix. Since the crystal size increases with striking temperature the bandgap also decreases with increasing crystal size, implying quantum confinement. The steepness of the absorption edge is related to crystal size of the $\mathrm{CdS} / \mathrm{CdSSe}$ and its uniform distribution in the glass matrix.

\section{Acknowledgements}

The authors would like to acknowledge the Department of Science and Technology (DST), Govt. of India, for financial support, Prof. T R N Kutty, Indian Institute of Science, Bangalore for the TEM analysis and Dr C V V Satyanarayana for the XRD analysis. Authors would like 
to thank the Executive Director, C-MET, Pune, for generous support.

\section{References}

Borrelli N F, Hall D W, Holland H J and Smith D W 1987 J. Appl. Phys. 615399

Ekimov A I and Onushchenko A A 1981 Pis' ma Zh. Eksp. Teor. Fiz. 34363

Ekimov A I et al 1993 J. Opt. Soc. Am. B10 100
Hache F, Richard D and Flytzanis C 1989 Appl. Phys. Lett. 55 1504

Lifshitz I M and Slyozov V V 1961 J. Phys. Chem. Solids 1935 Murugan A V, Sonawane R S, Kale B B, Apte S K and Kulkarni A 2001 Mater. Chem. \& Phys. 7198

Norris D J, Sacra A, Murray C B and Bawendi M G 1994 Phys. Rev. Lett. 722612

Persans P D, Lurio L B, Pant J, Lian G D and Hayes T M 2001 Phys. Rev. B63 5320

Potter Jr B G and Simmons J H 1988 Phys. Rev. B37 10838

Santhi S and Trojanek F 2005 Physica E27 38 